Tatiane Furukawa Liberato Universidade Federal de São Carlos

\author{
Thales Haddad Novaes de Andrade \\ Universidade Federal de São Carlos
}

\title{
Relações de gênero e inovação: atuação de mulheres nos NITs paulistas
}

Resumo: As últimas décadas presenciaram avanços importantes no que diz respeito à inserção e participação das mulheres no campo científico. Entretanto, estudos demonstram que essa participação ainda é menor que a masculina, indicando que as mulheres não avançam na carreira científica de forma igualitária. Partindo do pressuposto de que o crescimento expressivo do número de mulheres nas universidades do país revela que a mulher pode estar mais engajada em trabalhos relacionados ao campo da Ciência, Tecnologia e Inovação, neste artigo verificamos como esta participação tem acontecido na atuação dos Núcleos de Inovação Tecnológica (NITs) das Instituições Científicas e Tecnológicas (ICTs) paulistas, através de levantamento qualiquantitativo das mulheres neste campo. O intuito foi debater o tema permeado pela relação atual de universidade-empresa considerando o número de mulheres neste processo de inovação, e como um estudo dessa natureza pode ser ferramenta para maiores discussões e/ ou participações das mulheres no desenvolvimento da Ciência.

Palavras-chave: Mulheres e Núcleos de Inovação Tecnológica; Gênero e Ciência; Mulheres nos NITs; Gênero e Inovação

\section{Introdução}

No contexto de homem e mulher, a distinção do gênero corresponde às noções de masculinidade e feminilidade socialmente construídas, e o sexo às diferenças biológicas entre homens e mulheres. Apesar de ser considerado um exemplo de distinção construído a partir da divisão social do trabalho, ainda há predomínio de homens e mulheres em algumas funções justificadas por fatores biológicos. Por isso é questionável se essas justificativas não

\section{(c) (7)}

Esta obra está sob licença Creative Commons. 
escondem as diferenças historicamente construídas pela sociedade que são reproduzidas ao longo dos tempos.

De maneira geral, a Ciência é feita por homens e mulheres, onde há diferenças de gênero como em qualquer outra área do conhecimento, e cujas distinções de características biológicas ou fisiológicas não devem ser ignoradas. Historicamente, Jane E. Fountain (2000) acredita que as mulheres "inovadoras" são menos visíveis e pouco representadas em setores com responsabilidade primária pelo desenvolvimento científico e tecnológico mesmo em uma sociedade da informação.

Com o passar dos anos, esse quadro tem mudado, mas é possível dizer que o gênero na Ciência continua sendo uma extensão do gênero na sociedade construído historicamente. Isso porque as limitações que o gênero feminino sofre acabam justificando os índices de produtividade, as diferenças em determinadas áreas, os tipos de publicação e outros números que são aprendidos como "naturais", e são oriundos de diferenças biológicas e não de gêneros.

Para Maria Conceição da Costa (2006), a ausência das mulheres na Ciência diz respeito à predominância de uma ideologia que sustenta a objetividade, a neutralidade e a racionalidade da Ciência e a existência de poucas mulheres para escrever sobre a relação gênero e Ciência. Por essa razão, desvendar o feminino na construção do conhecimento vem ao encontro das preocupações de uma área ainda em construção no Brasil, Gênero e Ciência, mas fértil em abordagens e análises sobre a participação de mulheres na Ciência e na geração do conhecimento.

Assim, os estudos de Gênero e Ciência têm se caracterizado como uma corrente que visa analisar a Ciência a partir do referencial dos estudos feministas e de gênero e dos estudos sociais da Ciência. Eles são caracterizados por multidisciplinaridade e integrados por filósofas, historiadoras, biólogas, antropólogas etc. pautadas num questionamento profundo a respeito da Ciência que foi produzida até a atualidade e na discussão sobre a possibilidade de se fazer uma Ciência feminista. (Carlos CACERES; Kenneth Rochel de CAMARGO JR.; Fabíola ROHDEN, 2009)

Nesse sentido, a sociologia da Ciência acredita que essas relações entre Ciência e sociedade são recíprocas e de mão dupla e, por isso, a Ciência interfere no entendimento e na construção social do que é o gênero feminino. Daí a importância de reforçar essa relação entre gênero e Ciência, tanto do ponto de vista ideológico que abrange as dimensões de gênero e padrões de comportamento no âmbito das comunidades científicas, quanto à própria Ciência, que também contribui para desconstruir ou reforçar padrões de comportamento na sociedade.

Um dos principais temas colocados pela filosofia feminista recaiu sobre a distinção sexo/gênero: sexo é um aspecto natural, enquanto a noção de gênero é socialmente construída. A posição feminina humanista entende gênero como atributo de pessoa caracterizada essencialmente como uma substância ou um núcleo de gênero préestabelecido, sendo que a identidade é performativamente constituída. Por isso, a desconstrução da identidade não é a desconstrução da política; ao invés disso, ela estabelece como políticos os próprios termos pelos quais a identidade é articulada. (Carla RODRIGUES, 2005)

Considerando que as construções de gênero feitas pela sociedade estão presentes na Ciência, e a Ciência também influencia as construções sociais do gênero, a sociologia da Ciência pode representar uma área que desmistifica crenças como a divergência natural de homens e mulheres.

Na carreira científica, a primeira descrição das perspectivas da mulher é a sua presença na universidade. Mantendo tendência internacional, sobretudo em países 
desenvolvidos, observa-se que as mulheres do Brasil já formam larga maioria entre os estudantes universitários, acentuando a presença majoritária que já se verifica no país há mais de uma década. (Hildete Pereira de MELO, 2004)

Para Paula Mählck (2001), a investigação sobre as diferenças de gênero nas carreiras científicas tem sido uma área de interesse crescente nos últimos anos, mas apesar disso, poucos estudos demonstram o efeito dessas diferenças que têm se concentrado no impacto das organizações de pesquisa.

Pensando na esfera dessas instituições, este artigo discute a presença de mulheres nos Núcleos de Inovação Tecnológica (NITs) paulistas, especificamente os núcleos da Universidade Federal de São Paulo (Unifesp), Universidade Federal do ABC (UFABC), Universidade Federal de São Carlos (UFSCar), Universidade Estadual de Campinas (Unicamp), Universidade Estadual Paulista (Unesp) e Universidade de São Paulo (USP), tomando como referência o levantamento qualiquantitativo de mulheres atuantes na área de inovação das Instituições Científicas e Tecnológicas (ICTs) que contribuem significativamente com o avanço da Ciência brasileira, tendo como principais indicadores de C\&T o número de depósitos de pedidos de patentes. Nele, buscamos compreender, através de literatura estrangeira, a inclusão das mulheres nas carreiras de Ciência e tecnologia no Brasil, considerando a presença destas profissionais nos NITs, e as discussões atuais sobre a condição social e as diferenças existentes de gênero. Neste levantamento, chamamos a atenção para a existência de determinados discursos e práticas sociais produzidos socio-historicamente.

Os NITs paulistas surgiram entre os anos 2002 e 2013 nas principais universidades brasileiras como determinação de um contexto de iniciativas de incentivo ao avanço tecnológico, cuja Lei de Inovação' (Lei n 10.973, de 02/12/2004) objetivou criar melhores condições à constituição de parcerias entre universidades, institutos de pesquisas e empresas, estimulando a inovação no setor empresarial e facilitando o relacionamento entre estes atores. A Lei foi inserida em um contexto no qual uma série de países passou a discutir instrumentos que estimulassem empresas locais.

Entretanto, mesmo tendo a mesma finalidade - gerir sua política de inovação -, as universidades possuem diferentes modelos de NITs e dependem das especificidades de cada ICT ou consórcio de ICTs e dos mecanismos de transferência de tecnologia utilizados por elas. Entre os NITs considerados, a instituição com mais tempo de atuação é o Núcleo de Inovação Tecnológica da UNIFESP, que foi instituído em 2002. A partir daí surgiram a Agência de Inovação Inova UNICAMP em 2004, a Agência USP de Inovação em 2005, a Agência UNESP de Inovação em 2006, a Agência de Inovação da UFSCar em 2008, e mais recentemente a Inova UFABC - Agência de Inovação, em 2013.

De maneira geral, este artigo foi organizado em quatro seções. Na primeira e na segunda seção, elaboramos um referencial teórico que suscita perspectiva histórica da desigualdade de gênero na Ciência e as representações sociais deste conceito na academia. Num terceiro momento, apresentamos a atuação das mulheres nos NITs paulistas das ICTs, considerando as que exercem liderança, o perfil das gestoras e algumas características da área da inovação. E por fim, elaboramos as considerações finais justificando a análise qualiquantitativa como metodologia de investigação.

Em resumo, o artigo lida com as diferenças de gênero através de uma avaliação da participação feminina na inovação no âmbito das ICTs. O pressuposto subjacente é que,

\footnotetext{
1 Art. 10 Esta Lei estabelece medidas de incentivo à inovação e à pesquisa científica e tecnológica no ambiente produtivo, com vistas à capacitação e ao alcance da autonomia tecnológica e ao desenvolvimento industrial do País, nos termos dos arts. 218 e 219 da Constituição. Fonte: http://www.planalto.gov.br/ccivil_03/ _ato2004-2006/2004/lei/110.973.htm. Acessado em 30 de abril de 2015.
} 
assim como as carreiras acadêmicas, o trabalho dos NITs é um processo específico e longo, moldado pelo efeito cumulativo de eventos positivos e negativos que interagem com o tempo e por meio do qual pode ser considerado objeto de estudo.

\section{Perspectiva histórica da desigualdade de gênero na Clência}

Em meados dos anos 1980 e início de 1990, um estudo de caso ilustrou como colegas do sexo masculino viam uma mulher cientista através de filtros distintos de gênero. Eles ignoraram suas realizações científicas, reduzindo os talentos nas áreas de sociabilidade, família e comportamento - atributos femininos tradicionais, mas irrelevantes para o esclarecimento de capacidade científica. (Pnina Geraldine ABIR-AM, 2010)

O processo de conscientização que ajudou a libertar as mulheres na década de 1970 e levou a estabelecer o gênero como categoria analítica poderosa para os historiadores, foi muitas vezes ignorado por homens, que continuaram a ocupar a grande maioria das posições tecnocientíficas. Isso nos permite verificar que a maioria dos historiadores (masculinos) da tecnologia não está interessada em gênero, pois contribuem pouco para o combate aos estereótipos. Em contrapartida, as mulheres historiadoras da tecnologia e feministas teóricas de gênero assumem quase inteiramente o ônus da revisão do determinismo tecnológico que se tornou marca da história da tecnologia, uma vez separados da História da Ciência em 1957.

Abir-Am (2010) acredita que até 2010 foi possível verificar grande mudança na conscientização pública sobre a relação entre gênero e tecno-ciência, com a paridade de gênero como assunto de amplo debate público, cultural e simbólico. Embora a mudança radical na política de paridade de gênero continue a ser implementada em larga escala, a consciência sobre a importância da questão já mudou os termos do debate público para além da tolerância de preconceito do gênero.

A pergunta que ainda é feita nos dias atuais, especialmente no âmbito das universidades, com a presença de docentes do sexo feminino, é apresentada por Rosalind Chait Barnett e Laura Sabattini, (sem data) e questiona "onde estão as mulheres na Ciência?". Algumas respostas racionalizam o seu fraco desempenho, considerando que, segundo a história, as mulheres nunca fizeram contribuições significativas para as Ciências. Além disso, é forte o argumento de que as mulheres que buscam carreiras na Ciência comprometerão o seu bem-estar e o de suas famílias. No entanto, algumas respostas refletem tanto as mudanças sociais como os dados empíricos recentes, verificando novas evidências que sugerem que as chances das mulheres terem sucesso na Ciência dependem da estrutura da organização dentro da qual elas trabalham.

Por outro lado, Henry Etzkowitz e Carol Kemelgor (2001) acreditam na desigualdade de gênero na Ciência enquanto condição universal. Apesar de que a utilização dos recursos humanos na sociedade ser necessária para alcançar o desenvolvimento econômico e social, os autores fazem o mesmo questionamento sobre o motivo de haver tão poucas mulheres na Ciência, transcendendo os interesses de gênero, cuja era de crescimento baseado no conhecimento com questões semelhantes foi levantada em todo o mundo. Além disso, os autores postulam que a condição das mulheres na Ciência reflete paradoxos cuja participação parece aumentar e declinar sob a expansão (ou retração) do sistema econômico, o que leva a uma desigualdade de gênero universal. Ou seja, quando a Ciência não apresenta rigor, o número de mulheres aumenta. E ao se fazer Ciência com potencial para não só melhorar status social, mas também o aumento de prestígio, dinheiro e outros tipos de poder, as mulheres tendem a ser excluídas. 
É nesta medida que Costa (2006) afirma que o processo de distanciamento das mulheres para com a Ciência, enquanto atividade sistematizada, começa no processo de socialização. Direcionadas para atividades consideradas "femininas", mesmo a entrada na carreira científica acaba esbarrando em outros constrangimentos, como a difícil escolha entre família, maternidade e carreira. A autora acredita que não se trata apenas de superar os constrangimentos criados, mas de reinventar a atividade, pois a questão da objetividade da atividade se confunde com a postura em direção à superação dos obstáculos.

Embora as formas de discriminação tenham diminuído nos últimos 30 anos, as barreiras sutis permanecem, pois, apesar do aumento da habilidade e conhecimento, as mulheres enfrentam a exclusão a partir de fontes informais de comunicação, pressões que seguem o modelo masculino, com conflito entre trabalho e papéis familiares, e tempo insuficiente para assumir cargos elevados que exigem dedicação. Apesar disso, Ełzkowitz e Kemelgor (2001) preveem um impulso em direção à igualdade das mulheres na Ciência e Tecnologia, tendo em vista que o indicador mais importante no futuro poderá ser não apenas um aumento em números, mas a adesão das mulheres aos cargos de liderança.

Fanny Tabak (2002) defende que essa exclusão das mulheres na Ciência se deve a barreiras culturais que foram sendo construídas ao longo da história da humanidade. Por isso é preciso motivar a integração das mulheres na Ciência atualmente. A autora acredita que a própria instituição científico-tecnológica ocidental é profundamente sexista ao ser construída sob valores de dominação e controle tipicamente masculinos. Ou seja, a mulher não é estimulada a se ver como cientista, pois há falta de conhecimento, por parte dela, durante os estudos do ensino médio, sobre o campo de atuação na Ciência - que é considerada área masculina. Além disso, preconceitos, casamento, filhos, gravidez, baixo salário, falta de chances para atingir posições mais altas e medo da pressão social são fatores que contribuem para o desestímulo da mulher na carreira científica. Já Elizabeth Bortolaia Silva (1998) estabelece a relação de gênero em Ciência e tecnologia com três temáticas principais: universalidade, políticas de localização, e políticas de mudança. Enquanto a universalidade prescreve relações monolíticas de Ciência e tecnologia, as perspectivas feministas (pós-estruturalista e pós-moderna) desafiam a racionalidade argumentando que as formas de saber e poder na sociedade são construções sociais com interesses específicos. Assim, mesmo estando no século XXI, a divisão do ser, fazer e perceber entre homens e mulheres é tida como natural, sendo que as estruturas sociais, valores e ideologias da sociedade ficam na tentativa de responder e justificar tais "diferenças".

Ao elaborar uma crítica feminista à Ciência, Margareth Rago (1998) acredita que os principais pontos recaem na denúncia de seu caráter particularista, ideológico, racista e sexista, considerando que a Ciência universal é historicamente androcêntrica, branca, ocidental, heterossexual e localizada nas classes mais privilegiadas da sociedade, desconsiderando aqueles que não pertencem a esse modelo de referência.

Todas essas considerações nos permitem relacionar a discussão de gênero na academia como uma "extensão" da questão de gênero na sociedade, pois, assim como as empresas e outras instituições sociais contribuem para a preservação das segregações de gênero, as instituições sociais (sindicatos, grupos políticos etc.) podem contribuir para a implementação de mudanças nos padrões de relações de gênero. No entanto, as instituições são feitas por pessoas, e as construções de gênero e de outras diferenças são carregadas para esses projetos de mudança "políticos e pessoais". Por isso, Silva (1998) sugere que é tempo de mudar a maneira de conceber as diferenças sociais se quisermos que as nossas realidades não sejam totalizadoras e não reflitam possibilidades de nãodominação, já que a preservação e o cuidado com as diferenças é parte do projeto de reconstrução de um mundo mais igualitário. 
Corroborando essa discussão, Jussara Prá e Eduardo Schindler, (2013) evidenciam aumento na participação das mulheres nos processos decisórios, visando refletir sobre os cenários institucionais orientados à conformação de políticas públicas a fim de corrigir desigualdades históricas e promover a equidade de gênero.

\section{Representações sociais do conceito de gênero na academia}

Na década de 1970, os trabalhos em teoria feminista começaram a aparecer em antropologia e sociologia, história, literatura e psicanálise, embora ainda não em disciplinas relacionadas com as Ciências naturais e/ou exatas.

Para Evelyn Fox Keller (1995), a questão de "gênero na Ciência" não figura entre estudos variados de mulheres, sexo e gênero na Ciência, mas entre os estudos históricos de gênero, linguagem e cultura na produção da Ciência. Para estes estudos, ela faz apelo especial ao esforço de integrar uma série de perspectivas analíticas que estão atualmente mal percebidas. A autora não privilegiou qualquer agenda política ou intelectual particular, mas ao contrário, deu espaço para todas as diferentes preocupações que estas subcategorias levantam, separadamente. O ponto principal é que o papel da ideologia de gênero é apenas um aspecto do papel constitutivo da linguagem, da cultura e ideologia na construção da Ciência e, portanto, embora as raízes de tais análises continuem protagonizando a teoria feminista, o seu lugar na história da Ciência deve ser tomado apenas como uma parte da investigação mais geral.

As Ciências modernas têm sido caracterizadas por duas imagens complementares e contraditórias, de acordo com Maria Margaret Lopes (1998): de um lado, o homem sério, de avental, no laboratório - imagem que evoca a objetividade como valor central da Ciência; e do outro lado, a imagem do aventureiro que enfrenta perigos na selva e no laboratório. Essa última imagem está menos conectada com as virtudes atribuídas à Ciência, mas fortemente associada aos ideais de masculinidade da cultura moderna europeia e ainda pouco considerada mesmo nesses estudos feministas de crítica às Ciências naturais.

Quando tratam das diferenças de gênero em produtividade de pesquisa,Giovanni Abramo, Ciriaco Andrea D'Angelo e Alessandro Caprasecca (2009) defendem que as diferenças de produtividade entre homens e mulheres na carreira científica sempre atraiu o interesse de ampla gama de pesquisadores e abrange pelo menos dois temas: psicocognitivo e sociológico. Durante as duas últimas décadas, as questões de diferenças de gênero em habilidades cognitivas foram abordadas por estudos de meta-análise verbal, espacial e habilidades matemáticas, que não indicam diferenciação em habilidades entre homens e mulheres, mas oferecem uma caracterização por tipologia de capacidade e contexto de aplicação.

Para as Ciências e, principalmente, no mundo da pesquisa, a presença feminina ainda parece limitada e relegada a papéis marginais, já que as mulheres representam apenas $1 / 6$ dos investigadores no setor privado e $1 / 3$ de toda a comunidade de docentes, embora essa representação tenha aumentado ao longo do tempo. Quanto à composição do corpo docente, as mulheres tendem a estar concentradas em papéis inferiores pois há apenas uma mulher para cada 3,5 homens nos altos escalões acadêmicos. Estas estatísticas têm estimulado estudos sociológicos para identificar e sugerir intervenções que equilibrem a situação, pensando nas possíveis causas como o menor número de mulheres entrando no campo, desigual oportunidade e discriminação sexual, ou menor desempenho em relação aos homens. Nesta última área, um dos achados mais consistentes, na literatura sobre pesquisa e produtividade, é que as mulheres tendem a ter taxas de publicação um pouco mais baixas do que os homens. (ABRAMO, D'ANGELO E CAPRASECCA, 2009) 
O desenvolvimento da Ciência e tecnologia, cuja taxa de crescimento dos últimos 50 anos tem se mantido, sente a necessidade de aumentar o número de pessoas (homens e mulheres) que se dedicam à investigação. Isso demonstra que a política de C\&T sofre um período crítico na maioria dos países e regiões do mundo, daí a urgência de estudar a situação das mulheres na Ciência, estabelecendo ampla informação sobre o sistema de C\&T para fornecer substâncias de análise baseadas em evidências políticas. Esse sistema de informação deve incluir bases de dados e indicadores que descrevam as condições em que as mulheres participam do sistema de C\&T, em diferentes países e regiões e que verifiquem se a política de gênero está no caminho certo. (UNESCO, 2007)

De acordo com a publicação Science, Technology and Gender: An International Report (UNESCO-2007), há uma falta de dados oficiais sobre Ciência, Tecnologia e Gênero, situação que restringe os esforços para conceber e implementar políticas voltadas às mulheres em C\&T, sobretudo as que procuram fornecer situação equitativa de trabalho. Em muitos países, os dados e indicadores são produzidos - por acadêmicos, ONGs e grupos de interesses especiais - mas são mal comunicados e recebidos ou não são levados em conta pelos órgãos de decisão nacionais. Por isso, embora os dados existentes mostrem que a situação das mulheres em C\&T ainda está longe da ideal, é essencial coletar mais e melhores dados sobre essa situação, a fim de realizar um diagnóstico completo que aprofunde estratégias, promova e valorize a sua contribuição. Mählck (2001) percebe pouco foco no impacto da organização de pesquisa sobre os investigadores e oferece nova abordagem da questão através da introdução de mapas bibliométricos combinados com dados sociológicos e entrevistas, levando em conta a organização de pesquisa, as experiências da individualidade, e o pesquisador.

A relutância de se considerar o gênero como relevante para a carreira chama a atenção para duas construções sociais: academia como uma instituição objetiva e neutra, onde a meritocracia está governando; e a norma da igualdade, que parece ser comum na maioria das sociedades acadêmicas. Para aceitar que o gênero desempenha um papel importante na prática de pesquisa, é necessário aceitar que a Ciência é socialmente tendenciosa, o que pode criar uma dissonância nos indivíduos, uma vez que questiona a fundação normativa da Ciência que argumenta que os talentos e processos de avaliação científica não devem ser socialmente influenciados pela classe, gênero, etnia/raça, orientação sexual, e assim por diante. (MÄHLCK, 2001)

Além disso, Mählck (2001) lembra que as pessoas podem estar sob diferentes tipos de pressão da comunidade científica, o que poderia tornar mais gratificante defender a norma do universalismo em vez de questioná-la. No entanto, o gênero parece ter importância quando se trata de situações diárias de trabalho, revelando ambivalência, já que, por um lado, contesta a norma de igualdade e meritocracia, e, por outro lado, é uma forma importante de categorizar e dar sentido ao mundo, o que inclui a separação de feminilidade e masculinidade em que o feminino é desvalorizado.

Essas considerações implicam no gênero como um ato de equilíbrio formado por pesquisadores, e que está muitas vezes enraizado na sua rotina de trabalho, tornando-se difíceis de identificar. Mas a autora acredita na necessidade de explorar mais o tema para se aproximar da compreensão do papel do gênero nas carreiras científicas.

Os dados dos últimos 20 anos têm demonstrado que, apesar de um número crescente de mulheres com cursos científicos e técnicos, "a representação de gênero na academia permanece desigual, com os homens ainda superando as mulheres em todos os níveis do corpo docente" (Rosalind Chait BARNETT e Laura SABATINI, sem data, p. 8) As autoras também lembram que os critérios de promoção na academia são especialmente susceptíveis à influência de avaliações subjetivas (e, portanto, a polarização do gênero), enquanto a 
pressão da indústria para alcançar resultados de negócios específicos (por exemplo, a criação de novos produtos) se concentra em normas mais explícitas e menos subjetivas, tais como a capacidade de trazer novas descobertas e produtos de sucesso no mercado.

Assim, o registro histórico mostra que, apesar de suas contribuições, as mulheres cientistas raramente recebem o reconhecimento proporcional. Mesmo que haja mais mulheres hoje do que no passado, a situação está longe de ser um problema especial da academia. Além disso, dirigindo-se à desigualdade de gênero na Ciência, com abordagem estrutural, a sub-representação das mulheres nas Ciências (na academia e na indústria) tem consequências importantes em todos os níveis: para as mulheres, instituições educacionais e empresas. E apesar destas "paredes invisíveis", mulheres cientistas têm feito importantes avanços em nível universitário. $\mathrm{E}$, por isso, são necessárias mudanças no sistema de revisão por pares, e em outras "paredes" se quisermos evitar o desperdício de talento de mulheres cientistas altamente capacitadas. Essas estratégias visam derrubar as barreiras que as mulheres ainda têm que enfrentar ao decidir seguir uma carreira específica.

No contexto particular da história da Ciência, Keller (1995) sugere que, para o futuro do gênero na Ciência, o esforço por parte das feministas para despertar a atenção dos historiadores para a importância do gênero, deve trabalhar com os pontos fortes de sua consciência política de gênero e irreverência para limites operacionais recebidos entre as disciplinas. Isso porque as feministas teóricas trouxeram lições poderosas que não podemos ignorar. Mas para avançar a análise de gênero na Ciência, essas forças devem ser integradas com as forças historiográficas mais convencionais.

\section{Atuação das mulheres nos NITs paulistas}

A percepção da situação feminina atual no campo científico se justifica, social e politicamente, face às alterações observadas nas últimas três décadas no perfil da qualificação profissional das mulheres brasileiras, observada na expressiva participação feminina no mercado de trabalho e na mobilização política em prol desta parcela da população. (MELO, Helena Maria Martins LASTRES, Teresa Cristina de Novaes MARQUES, 2004).

Com base nessas conceituações, levantamos a presença das mulheres que atuam nos Núcleos de Inovação Tecnológica (NITs) das principais Instituições Científicas e Tecnológicas (ICTs) do Estado de São Paulo, haja vista que as ICTs desempenham um importante papel no desenvolvimento técnico-científico, de acordo com as demandas da sociedade. Além disso, estas entidades produtoras de C\&T estão cada vez mais conscientes de seus compromissos sociais.

Nesse contexto, os Núcleos de Inovação Tecnológica das universidades e institutos de pesquisa, ou Agências de Inovação, como são popularmente conhecidos, figuram entre os principais mecanismos instituídos pela Lei de Inovação, como intermediadores no processo de gestão tecnológica nas universidades brasileiras. Essas estruturas são o campo deste estudo, partindo do pressuposto de que as áreas de atuação inerentes ao Núcleo contribuem para a disseminação da cultura da propriedade intelectual, haja vista sua relevante participação nacional em produção científica e depósito de patentes.

É importante mencionar que não há uma maneira única ou correta para estruturar ou otimizar a gestão de um Núcleo de Inovação, pois cada instituição deve construir uma estrutura que melhor atenda às suas próprias necessidades e realidades locais/regionais. (Marli Elizabeth Ritter dos SANTOS, Patricia Tavares Magalhães de TOLEDO; Roberto de Alencar LOTUFO, 2009) 
Nessa discussão, os autores postulam a necessidade do fortalecimento da política de C,T\&l em estreita colaboração com a política industrial, cuja necessidade inclui o componente de propriedade intelectual, para o conhecimento gerado ser incorporado em desenvolvimento, de forma a superar a histórica desarticulação entre essas duas políticas e a de desenvolvimento econômico no Brasil, que tem, nos últimos anos, intensificado o interesse pelos direitos de propriedade intelectual e a cooperação universidade/empresa. Considerando que a formação de equipes e a implantação de laboratórios para efetivação de pesquisas de ponta são atividades onerosas e de alto risco para a empresa, estando hoje restritas às universidades e centros de pesquisa, em grande parte com recursos públicos, ainda é incipiente o processo de geração de conhecimento e a transformação desse conhecimento em riquezas.

Assim, os Núcleos de Inovação Tecnológica se constituem numa instância institucional de gestão da Propriedade Intelectual e da Transferência de Tecnologia em ICTs, criando uma interlocução entre o pesquisador e o parceiro empresarial. Nesse contexto, os NITs concentram suas atividades nestas duas grandes práticas - a gestão da Propriedade Intelectual, através da proteção/registro de tecnologias (considerada função prioritária dos NITs); sendo esta o principal insumo da transferência e comercialização de tecnologias (considerado objetivo final do processo de inovação tecnológica - que permite o acesso da sociedade às tecnologias).

Para facilitar e fortalecer essa relação entre universidades e empresas, os NITs utilizam a Propriedade Intelectual como fonte de informação tecnológica e comercial, disseminando o uso das tecnologias a fim de fazer com que seu papel seja integralmente cumprido: que elas estejam disponíveis para a sociedade. Nesse contexto, além das análises sobre discriminação das mulheres na Ciência, a divulgação científica e/ou popularização da Ciência, que tem como objetivo a aproximação da produção científica com o 'público leigo' por meio da informação e difusão, tem se preocupado em contribuir para a visibilidade da participação feminina na geração do conhecimento. Nos países industrialmente mais avançados, a divulgação científica é antiga e se reporta aos mais diversos assuntos. Entretanto a divulgação científica relevou-se, ao longo das últimas quatro décadas, como uma importante atividade que populariza a Ciência. (COSTA, 2008)

Assim, para analisar a incidência no número de mulheres atuantes dentro das Agências de Inovação - independente da área em que estejam inseridas - optamos por levantar dados qualiquantitativos, tendo em vista que a perspectiva de gênero possibilita uma rica avaliação sobre a quantidade das mudanças que as mulheres experimentaram nas últimas décadas, considerando as transformações ocorridas em todas as atividades econômicas e, particularmente, no caso deste estudo, no mundo científico e tecnológico.

Por meio deste levantamento, foi possível perceber a prevalência de mulheres em quatro de seis NITs (com mais de $50 \%$ da equipe composta por mulheres), a igualdade em um deles (com até $50 \%$ da equipe composta por mulheres), e a inferioridade numérica de mulheres em apenas um Núcleo no estado de São Paulo (cujo número total de mulheres chega a ser $37 \%$ menor que o total de funcionários). Apesar disso, mesmo onde há menor quantidade de mulheres, a diferença entre gênero não foi intensa, como demonstramos no gráfico 1.

O contato com os Núcleos de Inovação foi feito por meio de telefone e e-mail, sendo que outros NITs de Instituições Científicas e Tecnológicas paulistas foram contatados, mas não aceitaram participar da pesquisa. Os dados dos gráficos são referentes ao mês de junho de 2015. 
Gráfico 1 - Mulheres nos Núcleos de Inovação Tecnológica do estado de SP

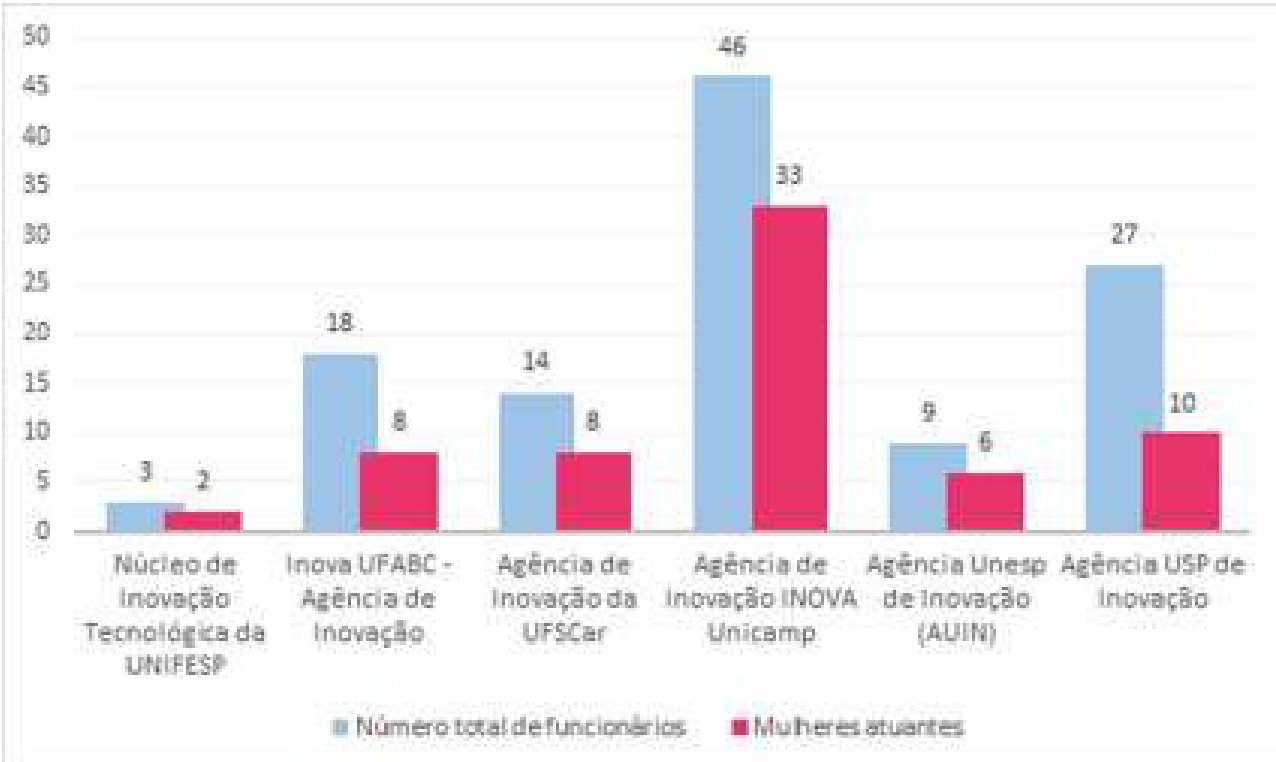

Fonte: Elaboração dos autores (2015)

A prevalência no número de mulheres se deu em quatro núcleos paulistas representados pelo Núcleo de Inovação Tecnológica da Unifesp, localizado na cidade de São Paulo, sendo mais da metade de sua equipe composta por mulheres $-67 \%$ dos colaboradores da instituição; na Agência de Inovação da UFSCar em São Carlos, com público feminino composto por $57 \%$ de mulheres entre seus funcionários; na Agência de Inovação INOVA Unicamp, em Campinas, com $72 \%$ dos funcionários representados pelas mulheres; e na Agência Unesp de Inovação (AUIN), em São Paulo, também com 67\% de sua equipe composta por mulheres. No entanto, na Inova UFABC - Agência de Inovação, o índice de mulheres é de $44 \%$, e na Agência USP de Inovação $37 \%$, ambas em São Paulo, demonstrando número inferior de mulheres neste campo de atuação. Em todos os NITs, os dados considerados englobam homens e mulheres que atuam como bolsistas, estagiários e contratados.

Apesar do maior número de mulheres prevalecer entre os NITs paulistas, a segregação vertical e horizontal podem sugerir diferença de características e habilidades entre gêneros, o que explicaria a exclusão das mulheres de algumas ocupações - características que também explicariam as diferenças de gênero na academia e na atividade científica (Gilda OLINTO, 2011 , p. 71). Além disso, é importante lembrar que toda a literatura sugere que o distanciamento entre homens e mulheres na Ciência é um processo que envolve diversos tipos de ganhos que beneficiam os homens como a promoção, a obtenção de bolsas de estudo, a ocupação de cargos de chefia ou liderança, além dos ganhos salariais. São vários os indícios de que, através de alguns mecanismos sutis que se estabelecem no ambiente científico, criam-se barreiras para as mulheres, dificultando a sua progressão profissional. Muitos destes mecanismos não seriam percebidos ou conscientizados pelas próprias mulheres, pois são comportamentos culturalmente enraizados e internalizados por aqueles que estão atuando no campo científico, o que significa que as próprias mulheres podem estar contribuindo para a sua perpetuação (OLINTO, 2011) 
No caso dos Núcleos de Inovação Tecnológica das ICTs do Estado, a prevalência de mulheres tem sido notada nos últimos anos com boa parte da equipe composta por pessoas do gênero feminino, sendo que os dados das posições de liderança, no entanto, evidenciam pouco predomínio, a exemplo do percentual do gráfico 2 , que relaciona a quantidade de mulheres gestoras com a quantidade total de mulheres em cada NIT.

Gráfico 2 - Mulheres em cargos de gestão nos NITs

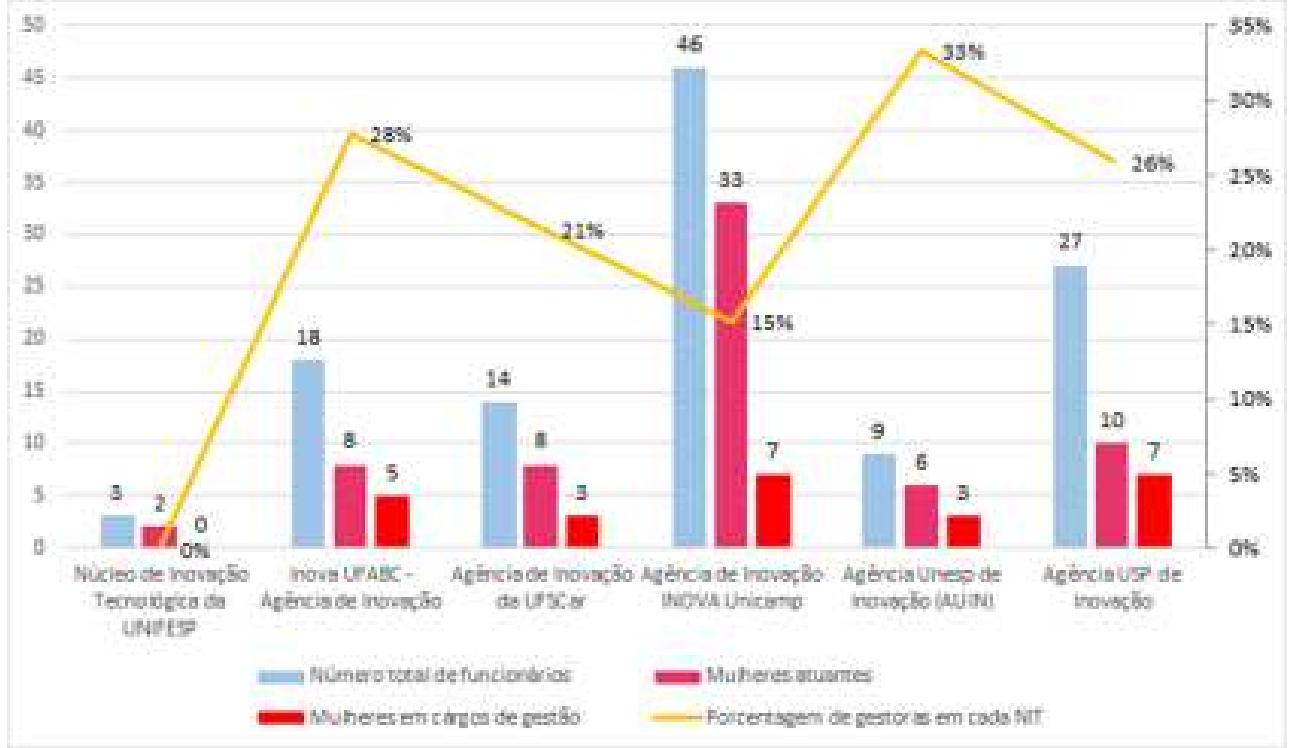

Fonte: Elaboração dos autores (2015)

Apesar do dado decadente, o único NIT que não possui nenhuma posição de liderança ocupada pelo gênero feminino é o Núcleo de Inovação Tecnológica da Unifesp que, de três funcionários totais, possui duas mulheres (mais da metade de seu total), mas nenhuma atuando como líder. O percentual zerado considera tanto a relação de mulheres pelo total de funcionários, quanto a relação de mulheres gestoras pela quantidade de mulheres atuantes.

Na Agência USP de Inovação, no entanto, esse dado possui relevância, considerando que dos 27 funcionários totais, apenas dez são mulheres, sendo que sete ocupam posição de liderança, o que corresponde a $70 \%$ de gestoras no âmbito do público feminino, número elevado, se considerarmos que apenas $26 \%$ deste Núcleo é composto por mulheres. 0 mesmo acontece com a Inova UFABC - Agência de Inovação, considerando as oito mulheres de 18 funcionários totais, sendo que cinco ocupam cargo de liderança entre a Coordenação Geral, e os cargos de Chefias dos setores de Projetos, Assessoria de Cooperações Institucionais e Convênios, Divisão de Inteligência Estratégica e Divisão de Propriedade Intelectual, representando $28 \%$ do percentual total de funcionários, de $63 \%$ das mulheres consideradas atuantes.

Já a Agência Unesp de Inovação (AUIN), que conta com seis mulheres entre nove funcionários totais, possui três mulheres nos maiores cargos de gestão do NIT, dentre os quais Diretoria Executiva, Gerente de Propriedade Intelectual e Gerente de Transferência de Tecnologia, que são, portanto, representadas por $33 \%$ do seu público, percentual que 
cresce consideravelmente, classificando $50 \%$ das mulheres gestoras frente à quantidade de mulheres que atuam no NIT.

Os dados apresentaram menor diferencial em percentual nos únicos dois Núcleos que estão localizados em cidades do interior do Estado: a Agência de Inovação da UFSCar em São Carlos e a Agência de Inovação INOVA Unicamp em Campinas. Na UFSCar, as oito mulheres, do total de 14 funcionários só são representadas por três líderes, atuantes entre Diretora Executiva, Coordenadora de Propriedade Intelectual e Secretária da Diretoria. O percentual é pouco ascendente de $38 \%$ das mulheres em cargos de gestão, considerando o total de mulheres, frente a $21 \%$ de mulheres gestoras considerando o número total de funcionários entre homens e mulheres. Já na Unicamp, a INOVA é considerada a maior agência do Estado, e uma das que mais possui mulheres atuantes, tendo como base o percentual total de funcionários. No entanto, apenas sete, entre 33 mulheres, detêm posição de liderança, o que representa apenas $15 \%$ do total de funcionários, percentual que cresce muito pouco diante de $21 \%$ de mulheres líderes frente às mulheres atuantes neste NIT.

Um dado que justifica o tamanho e a quantidade de funcionárias de algumas agências é o tempo de atuação nestas instituições dentro das ICTs brasileiras. Essas ICTs surgiram entre os anos 2000 e 2013, em um período em que muito se discutia sobre a questão da gestão tecnológica nas universidades, sobretudo, com da Lei de Inovação que instituiu, em 2004, os Núcleos como mecanismos intermediadores e responsáveis pelas questões da Propriedade Intelectual e Transferência de Tecnologias no âmbito das universidades.

Quase paralelamente à Lei, a Agência de Inovação INOVA Unicamp foi fundamentada em 2003 e instituída em 2004 e a Agência USP de Inovação surgiu em 2004 e foi consolidada em 2005. Ambas as instituições estaduais possuem características similares quando se considera o total de mulheres atuantes no NIT de acordo com a quantidade total de funcionários, sendo $15 \%$ e $26 \%$ respectivamente, apesar da USP apresentar maior percentual se considerarmos a prevalência de cargos mais elevados do sexo feminino. Além disso, ambas possuem Conselhos Superiores, responsáveis pelas atividades do Núcleo nas decisões relativas às políticas de Propriedade Intelectual. No caso da Agência USP de Inovação, o Conselho Superior possui 13 membros, sendo cinco mulheres, e o Conselho Executivo oito membros sendo apenas uma mulher. No total, são apenas seis mulheres entre 21 membros dos Conselhos da Agência USP.

Já a Agência de Inovação da UFSCar, cuja origem se deu em 2007, instituída em 2008, aconteceu quase conjuntamente ao surgimento da Agência Unesp de Inovação em 2006, instituída em 2007. Elas também possuem características equivalentes quando consideram a quantidade de mulheres no percentual total $-21 \%$ de mulheres da UFSCar e $33 \%$ na Unesp, percentuais que crescem pouco com relação às mulheres gestoras, sendo $38 \%$ de líderes mulheres na UFSCar e 50\% na Unesp. As duas Agências possuem em seu mais alto nível de gestão - Diretoria Executiva - mulheres à frente da instituição. Além disso, apesar de número menor de funcionários totais, a Unesp não conta atualmente com nenhum trabalho em Conselho, e, portanto, nenhuma mulher atuante no acompanhamento destes resultados da Universidade, no setor da inovação. Estes órgãos são responsáveis por elaborar recomendações e pareceres, bem como participar do direcionamento estratégico da Universidade nesta área. Já a Agência de Inovação da UFSCar submete todos os pedidos de proteção por Propriedade Intelectual à Comissão Especial de Propriedade Intelectual (COEPI), que é responsável por analisar e emitir parecer sobre a viabilidade técnica e econômica dos pedidos de proteção de Propriedade Intelectual. A Comissão é composta por quatro membros da comunidade acadêmica da UFSCar, de diferentes áreas do conhecimento, designados pelo Reitor (Portaria GR $n^{\circ} 823 / 08$ ), que atualmente conta com seis membros no total, sendo apenas duas mulheres.

12 Revista Estudos Feministas, Florianópolis, 26(2): e41763 
No caso do Núcleo de Inovação Tecnológica da Unifesp, que surgiu em 2000 e foi instituído como Núcleo somente em 2002, apesar de ser o NIT mais antigo, está em processo de reformulação atualmente, e conta com apenas três funcionários atuantes, sem trabalho acompanhado por Comissão ou Conselho da área. É também o único NIT que não possui nenhuma mulher em cargo de liderança.

Já a Inova UFABC - Agência de Inovação, que é o NIT mais recente do Estado, criado em 2010 e instituído em 2013, possui Conselho Técnico Científico com 12 membros da UFABC, sendo quatro mulheres neste âmbito. O Conselho Técnico Científico - CTC é o órgão de apoio executivo, propositivo e consultivo do NIT, cujas principais atribuições envolvem estabelecer o planejamento estratégico, propor ações e atividades que facilitem ou viabilizem alcançar suas finalidades, e analisar e emitir pareceres sobre as atividades desenvolvidas na Agência. Também compete ao CTC realizar análise crítica das ações e atividades desenvolvidas na Agência de Inovação e a indicação de consultores técnicos ad hoc, internos ou externos a UFABC, para emitir pareceres e subsidiar ações da Agência de Inovação. O Conselho é composto por: Coordenador ou Vice-Coordenador da Agência de Inovação, como presidente do CTC e membro; Chefe de cada Divisão Técnica; um representante de cada Centro, indicado pela Direção do Centro; um representante indicado pela Pró-Reitoria de Pós-Graduação; um representante indicado pela Pró-Reitoria de Planejamento e Desenvolvimento Institucional e um representante indicado pela Pró-Reitoria de Extensão. ${ }^{2}$

De maneira geral, o percentual de mulheres em posições de liderança não cresceu em relação ao percentual de mulheres atuantes nos NITs, mas a prevalência de mulheres se manteve no mesmo nível quando considerados os mais altos cargos de gestão, elencados no gráfico 3 como Diretoria Executiva e/ou Coordenação Geral, onde verificamos que $50 \%$ dos Núcleos analisados são dirigidos por uma pessoa do gênero feminino - em duas universidades federais e uma estadual.

Gráfico 3 - Mulheres na direção/coordenação dos NITs

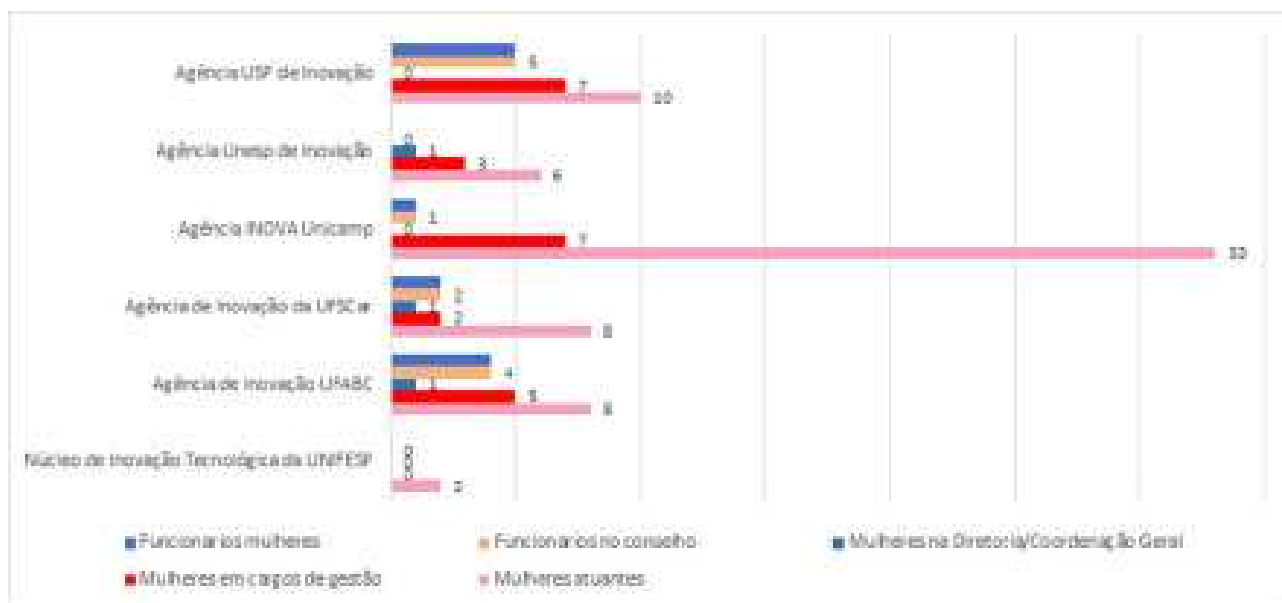

Fonte: Elaboração dos autores (2015)

\footnotetext{
${ }^{2}$ As informações sobre este Conselho constam no site da Inova UFABC - Agência de Inovação em: http:// inovacao.ufabc.edu.br/sobre-a-inovaufabc/ctc-conselho-tecnico-cientifico.
} 
Todas as informações sobre o percentual de mulheres nos NITs, o tempo de atuação de cada Núcleo, além do posicionamento destas mulheres dentro das instituições envolvem diferentes aspectos a respeito do que pode ser contextualizado frente à atuação feminina no âmbito acadêmico, lidando com a Ciência e, especificamente, liderando trabalhos com inovação.

No caso dos três Núcleos liderados por homens - NITs da USP, Unicamp e Unifesp -, que estão entre os dois maiores Núcleos do estado, o mais alto nível de liderança conta com dois diretores e um coordenador, sendo que, considerando a experiência profissional destes gestores, os três possuem diferentes tempos de atuação dentro das universidades: um possui mais de duas décadas, outro mais de três décadas, e o último possui mais de quatro décadas de experiência na universidade. Mesmo considerando o tempo "de casa", os diretores ocuparam essa posição apenas em 201 1, 2013 e 2015.

No entanto, no caso das mulheres que estão em cargos mais elevados - dentro dos NITs da Unesp, UFSCar e UFABC -, as características de cada gestora não são equivalentes. Na Unesp, o mais alto cargo - de Diretora Executiva - é ocupado por uma docente com cerca de quatro décadas de experiência na área de Ciências Farmacêuticas e Química, que assumiu esta posição em 2012, mas já havia sido vice-diretora de 2009 a 2011 , acumulando diversas experiências com inovação. Na UFSCar, a Diretora Executiva da Agência de Inovação possui mais de duas décadas de experiência em Engenharia de Produção, Administração e Gestão da Ciência e Tecnologia, ocupando o cargo desde 2012, com toda experiência acadêmica voltada para a área de inovação tecnológica e empreendedorismo. A diretora havia ocupado o mesmo cargo de 2008 a 2009, sendo a integrante responsável pela criação do Núcleo de Inovação Tecnológica da universidade. Já no caso da Inova UFABC, o mais alto cargo é ocupado por coordenadora com experiência de mais de uma década em Administração e Política Científica e Tecnológica, que lecionou em diferentes universidades desde 2002 e entrou na coordenação do Núcleo em 2013.

A trajetória destas gestoras possui perfil bastante diverso, se considerarmos que uma delas atua há mais de 40 anos em sua área de formação, outra possui quase 30 anos e a mais recente possui mais de 10 anos de experiência. No entanto, a Unesp e a UFSCar possuem similaridades, se forem considerados o tempo e a experiência em atividades relacionadas à gestão de inovação tecnológica, que podem ter contribuído para que estas gestoras estejam à frente dos Núcleos atualmente, como a coordenação da região sudeste do Fórum Nacional de Gestores de Inovação e Transferência de Tecnologia (Fortec) e a representação da International Union of Pure and Applied Chemistry (IUPAC) - organismo internacional que lida com as questões globais envolvendo as Ciências Químicas. As titulações e lideranças destas mulheres gestoras também são complementadas com outras experiências de liderança como a Chefia de um Departamento e a Diretoria Executiva de uma Fundação de Apoio Institucional.

Esses dados demonstram que as mulheres cientistas que trabalham no mundo hierárquico da academia podem deter posições de liderança, mas um caminho para a compreensão do sucesso ainda pode ser questionado em alguns campos da Ciência. Considerando as experiências das mulheres através do tempo, Barnett e Sabattini (sem data) acreditam que as oportunidades nas áreas científicas mudaram com base em normas sociais e estruturas educacionais e organizacionais.

Por isso, falar de gênero nos trabalhos científicos reflete ambiguidades que acompanham a inserção das mulheres no campo profissional da Ciência. Afinal, as diferenças no âmbito profissional pautam as principais discussões sobre a representação do gênero feminino, mas os mecanismos de segregação horizontal e vertical de gênero

14 Revista Estudos Feministas, Florianópolis, 26(2): e41763 
ainda separam homens e mulheres em nichos acadêmicos e podem limitar a progressão da mulher na Ciência.

A exemplo da construção de indicadores, Costa (2006) acredita que os dados recentes no Brasil apontam que as mulheres são maioria até o pós-doutorado e, no corpo docente, sua participação é equilibrada entre os doutores e os livre-docentes e elas são minoria entre os professores titulares. Já na coordenação de importantes pesquisas coletivas, as mulheres coordenaram cerca de $40 \%$ de grandes projetos. Embora esse número seja relevante, entrevistas afirmam que não existe, de fato, um preconceito explícito, sendo que os homens continuam agindo de forma a garantir a hegemonia masculina nos postos mais elevados das Ciências.

De maneira geral, no caso da atuação dos Núcleos de Inovação Tecnológica nas universidades paulistas - carreira que permeia o relacionamento universidade-empresa , a distribuição proporcional entre os sexos pode auxiliar possíveis estudos que levantem as dificuldades enfrentadas pelas mulheres no ambiente científico das ICTs, tendo em vista que, em outros setores e departamentos, a desproporção limita as chances das mulheres na dedicação à pesquisa e à publicação.

\section{Considerações finais}

Para Helena Hirata e Danièle Kergoat (2007), a superação das diferenças entre homens e mulheres no trabalho de maneira geral, e na Ciência em particular, requer o incentivo a estudos que podem focalizar os diversos aspectos da divisão sexual do trabalho que se estabelece na mais tenra idade - na definição de tarefas domésticas - até as diferenças que se determinam ao longo da experiência escolar e ocupacional, incluindo as posições ocupadas nas mais altas hierarquias profissionais.

Por isso, Costa (2008) defende que as análises sobre gênero e Ciência passem a considerar não apenas os aspectos institucionais da participação das mulheres nas práticas científicas (indicadores de produtividade), mas, fundamentalmente, nos aspectos contextuais e de cultura científica de diferentes áreas disciplinares.

É, portanto, necessário descer até os cenários científicos para ver como os quadros femininos adquirem visibilidade e identificar suas formas de inserção e certificação, o que demanda um olhar mais pontual e circunstancial.

No caso do trabalho com os NITs das ICTs paulistas, este artigo não confirmou a presença de diferenças significativas na atuação entre homens e mulheres da população de investigação, considerando que a literatura dedicada à análise da diferença, em qualquer tipo de atuação que lide com instituições de pesquisa entre os gêneros, tende a indicar melhor desempenho dos homens. Neste caso, as diferenças são menores do que em grande parte da literatura, confirmando tendência para o declínio da desigualdade.

No entanto, apesar de que quantidade de mulheres seja equivalente e, algumas vezes, superior dentro dos Núcleos, é possível questionar se, para haver progressão na carreira de maneira que a mulher conquiste o topo do nível hierárquico dentro da instituição, são necessários alguns fatores adicionais como o tempo de atuação, titulações e influência acadêmica para que ela "prove" que tem qualificação profissional para exercer um cargo de gestão - esforço que não é tão latente para o gênero masculino.

Neste âmbito, nas universidades mais tradicionais, como a UFSCar, Unicamp, Unesp e USP, apesar de configuração semelhante, que apresenta maior presença feminina em seus Núcleos, com algumas mulheres gestoras, apenas a Unesp e a UFSCar são comandadas por uma mulher, ambas com bastante experiência e influência profissional. A UFABC é a única universidade que possui um NIT liderado por uma mulher com perfil diferenciado - 
experiência recente com a docência e menor quantidade de trabalhos publicados em sua área de atuação. Já os NITs comandados por pessoas do gênero masculino - da USP, Unicamp e Unifesp - apresentam praticamente as mesmas características, com diretores/ coordenadores acadêmicos reconhecidos nacionalmente e, às vezes, internacionalmente, sendo que apenas a USP e a Unicamp são consideradas mais tradicionais no que diz respeito ao trabalho de gestão do NIT.

Assim, apesar de identificar características nos cargos de chefia ocupados pelas mulheres dos NITs, não foi possível prever se os gêneros possuem diferentes representações setoriais significativas pois, embora a atuação de homens e mulheres seja semelhante, este artigo não identificou se existem setores específicos dos NITs em que o desempenho das mulheres não demonstra ser inferior, tendo em vista que essas não foram quantificadas em determinadas áreas como Proteção à Propriedade Intelectual ou Transferência de Tecnologia.

Com o intuito de dar início a estudos mais aprofundados sobre questões de gênero e Ciência em organizações de pesquisa científico-tecnológicas como as universidades, ou em espaços específicos como os NITs, este trabalho buscou compreender a prevalência de mulheres que lidam com dois ambientes distintos: a academia e a indústria. $O$ resultado indicou que as ICTs não apresentaram diferença em números quanto à capacidade do trabalho feminino com a inovação porque os NITs analisados demonstraram equilíbrio na quantidade de mulheres quando comparada ao total de funcionários e, por isso, com alta capacidade de inovação.

De modo geral, pode-se concluir que as diferenças de gênero na atuação dos NITs paulistas, a exemplo das instituições federais Unifesp, UFABC, UFSCar, e estaduais como Unicamp, Unesp e USP, não apontam para uma clara supremacia masculina. Além disso, a atuação na Ciência, assim como o desempenho das mulheres no âmbito das ICTs, está longe de indicar diferenças significativas entre os sexos e sugerir habilidades específicas inerentes a homens e mulheres.

Entretanto, ainda falta muito para que ocorra a desconstrução de certos discursos e valores científicos. O presente estudo pretendeu levantar questões sobre esses aspectos que precisam de uma atualização constante.

\section{Referências}

ABIR-AM, Pnina Geraldine. "Gender and Technoscience: A Historical Perspective". Journal of Technology Management \& Innovation. Universidad Alberto Hurtado, Facultad de Economía y Negocios, Waltham, v. 5, n. 1, p. 152-165, Fevereiro, 2010. Disponível em: https://jotmi.org/index.php/GT/article/view/art150/531. Acessado em 30 de maio de 2015.

ABRAMO, Giovanni; D'ANGELO, Ciriaco Andrea; CAPRASECCA, Alessandro. "Gender differences in research productivity: a bibliometric analysis of the Italian academic system". Scientometrics, Vol. 79, No. 3, (2009), p. 517-539. Jointly published by Akadémiai Kiadó: Budapest and Springer: Dordrech. DOI: 10.1007/s1 1 192-007-2046-8. Disponível em: https:/ /link.springer.com/article/10.1007/s 11 192-007-2046-8. Acessado em 2 de abril de 2015.

BARNETT, Rosalind Chait; SABATTINI, Laura. A Short History of Women in Science: From Stone Walls to Invisible Walls. Chapter prepared for the American Enterprise Institute. Disponível no link: http://www.brandeis.edu/barnett/docs/7654.PDF. Acessado em 29 de maio de 2015.

CACERES, Carlos; CAMARGO JR., Kenneth Rochel de; ROHDEN, Fabíola. Ciência, Gênero e Sexualidade. Artigo preparado para o Diálogo Latino-Americano sobre Sexualidade e Geopolíica, Rio de Janeiro, 24-26 ago. 2009. Disponível no link: http://www.sxpolitics.org/ 


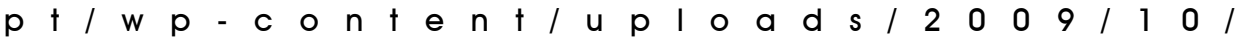
ciencia_genero_sexualidade_final_kenneth_caceres_fabiola.pdf.

COSTA, Maria Concêição da. "Ainda somos poucas: exclūão e invisibilidade na Ciência". Cadernos Pagu n 27. On-line version, ISSN 1809-4449. Campinas, July/Dec. 2006. Disponível em http://www.scielo.br/scielo.php?pid=S0104$83332006000200018 \&$ script $=$ sci_arttext\&tIng=esja.org. Acessado em 02 de junho de 2015.

"Divulgando a visibilidade das mulheres na Ciência". História, Ciências, SaúdeManguinhos, On-line version, ISSN 1678-4758 v. 15, suplemento, p. 289-293, jun. 2008. Disponível em http://www.scielo.br/scielo.php?script=sci_arttext\&pid=\$010459702008000500017. Acessado em 01 de maio de 2015.

ETZKOWITZ, Henry; KEMELGOR, Carol. "Gender inequality in science: a universal condition?". Minerva Journal Article 39, 153-1 74, Kluwer Academic Publishers. Printed in Netherlands. 2001.

FOUNTAIN, Jane E. "Constructing the information society: women, information technology, and design." Technology in Society. Elsevier, Cambridge, v. 22, n. 1, p. 45-62, Janeiro, 2000. Disponível em: https://www.sciencedirect.com/science/article/pii/ S0160791X99000366\#. Acessado em 28 de maio de 2015.

HIRATA, Helena; KERGOAT, Danièle. "Novas configurações da divisão sexual do trabalho". Cadernos de Pesquisa, São Paulo, v. 37, n. 132, p. 595-609, set/dez, 2007.

KELLER, Evelyn Fox. "Gender and Science: Origin, History, and Politics". Constructing Knowledge in the History of Science. The University of Chicago Press on behalf of The History of Science Society, Osiris, Chicago, 2nd Series, v. 10, pp. 26-38, 1995.

LOPES, Maria Margaret. "'Aventureiras' nas Ciências: refletindo sobre gênero e história das ciências naturais no Brasil." Cadernos Pagu, Campinas, n. 10, pp. 345-368, 1998. Disponível em: https://periodicos.sbu.unicamp.br/ojs/index.php/cadpagu/article/view/ 4689345. Acessado em 01 de maio de 2015.

MÄHLCK, Paula. "Mapping Gender Differences in Scientific Careers in Social and Bibliometric Space". Science, Technology, \& Human Values. Spring, Sage Publications, Inc. 2001, v. 26, n०. 2, 167-190.

MELO, Hildete Pereira de. "Gênero e perspectiva regional na educação superior brasileira". In: INEP. SECRETARIA ESPECIAL DE POLÍTICAS PÚBLICAS PARA AS MULHERES (Org.). Anais Simpósio Gênero e indicadores da educação superior brasileira. Brasília: INEP, v. 1, p. 63-84, dez., 2004.

LASTRES, Helena Maria Martins; MARQUES, Teresa Cristina de Novaes. "Gênero no Sistema de Ciência, Tecnologia e Inovação no Brasil". Gênero, Niterói, v. 4, n. 2, pp.: 7394, $1^{\circ}$ semestre de 2004. Disponível em: http://www.revistagenero.uff.br/index.php/ revistagenero/article/view/247. Acessado em 28 de maio de 2015.

OLINTO, Gilda. "A inclusão das mulheres nas carreiras de ciência e tecnologia no Brasil". Revista Inclusão Social, Brasília, DF, v. 5 n. 1, p.68-77, jul./dez. 2011 . Disponível em: http:/ /revista.ibict.br/inclusao/article/view/1667/1873. Acessado em 8 de junho de 2015.

PRÁ, Jussara Reis; SCHINDLER, Eduardo. Políticas Públicas de gênero e novas institucionalidades. Encontro Internacional Participação, Democracia e Políticas Públicas: aproximando agendas e agentes Araraquara - SP - UNESP 23 a 25 de abril de 2013. Disponível em : http://www.fclar.unesp.br/Home/Pesquisa/GruposdePesquisa/ participacaodemocraciaepoliticaspublicas/encontrosinternacionais/pdf-st08-trabaceito-0595-14.pdf. Acessado em 3 de junho de 2015.

RAGO, Margaret. "Epistemologia feminista, gênero e história". In: PEDRO, Joana Maria; GROSSI, Miriam (Orgs.). Masculino, feminino, plural. Florianópolis: Editora Mulheres, 1998. 
Disponível em: http://projenpq.mpbnet.com.br/textos/epistemologia_feminista.pdf. Acessado em 30 de maio de 2015.

RODRIGUES, Carla. "Butler e a desconstrução do gênero". Revista Estudos Feministas. Florianópolis, 2005, v. 13 n. 1, 179-183. Jan./Apr.

SANTOS, Marli Elizabeth Ritter dos; TOLEDO, Patricia Tavares Magalhães de; LOTUFO, Roberto de Alencar Lotufo (Orgs.). Transferência de Tecnologia: estratégias para a estruturação e gestão de Núcleos de Inovação Tecnológica. Campinas: Komedi, 1a. edição, v. 1. p. $350,2009$.

SILVA, Elizabeth Bortolaia. "Desconstruindo gênero em Ciência e tecnologia." Cadernos Pagu. Campinas, n. 10, pp. 7-20, 1998.

TABAK, Fanny. O laboratório de Pandora: estudos sobre Ciência no feminino. Rio de Janeiro: Garamond, 2002.

UNESCO. Science, Technology and Gender: An International Report. Chapter 5 - Information on STG: Data, Statistics and Indicators, 137-156, 2007. Disponível em http:// unesdoc.unesco.org/images/0015/001540/154027e.pdf. Acessado em 03 de janeiro de 2015.

[Recebido em 09/1 1/2015

reapresentado em 13/03/2017

e aprovado em 09/11/2017]

Gender Relations and Innovation: Women acting in TTO's in São Paulo

Abstract: The last decades have witnessed important advances regarding integration and participation of women in the scientific field. Thus, assuming the significant growth in the number of women in universities in Brazil reveals they may be more engaged in work related to the field of Science, Technology and Innovation, in this article we see how that participation has happened within Technology Transfer Offices (TTOs) located in Scientific and Technological Institutions (STI) in the state of São Paulo, through quantitative and qualitative evaluation of the women in this field. The purpose was to discuss the themes permeating the current relationship between universityindustry considering the number of women in the innovation process, as well as how a study of this nature can be a tool for further discussion and/or participation of women in the development of Science.

Keywords: Women and Technology Transfer Offices; Gender and Science; Women in TTOs; Gender and Innovation

Tatiane Furukawa Liberato (tatyliberato@gmail.com) é doutora em Ciência, Tecnologia e Sociedade pela Universidade Federal de São Carlos (UFSCar), mestra em Divulgação Científica e Cultural pela Universidade Estadual de Campinas (Unicamp) e atua como analista de comunicação da Agência de Inovação da UFSCar.

Thales Haddad Novaes de Andrade (thales@ufscar.br) é docente do Departamento de Ciências Sociais da Universidade Federal de São Carlos (UFSCar) e bolsista produtividade do Conselho Nacional de Desenvolvimento Científico e Tecnológico (CNPq).

18 Revista Estudos Feministas, Florianópolis, 26(2): e41763 